\title{
Correction to: Comments on Chavent et al.: Renovascular hypertension: results in adulthood of renal autotransplantation performed in children
}

\author{
Nellie Della Schiava ${ }^{1} \cdot$ Patrick Lermusiaux $^{1}$
}

Published online: 5 February 2018

(C) IPNA 2017

\section{Correction to: Pediatr Nephrol}

https://doi.org/10.1007/s00467-017-3723-3

In the name of the first author, the element "Della" was misinterpreted as a second given name. In fact, it is part of her surname.

The online version of the original article can be found at https://doi.org/ 10.1007/s00467-017-3723-3.

Nellie Della Schiava

dellaschiava.nellie@neuf.fr

1 Departement of Vascular and Endovascular Surgery, Hôpital

Edouard Herriot, 5 Place d'Arsonval, Lyon Cedex 03, France 